DOI: 10.1515/jolace-2015-0001

\title{
Forging new pathways for research on language learning motivation
}

\author{
Françoise Raby \\ LAIRDIL, University of Toulouse 3, France \\ fraby@lairdil.fr
}

\begin{abstract}
Research on motivation in the field of applied linguistics seeks to better understand how and why learners become involved in learning activities and maintain their efforts in this regard. Dörnyei provided a seminal model drawing essentially from cognitive and social psychology (Dörnyei, 2001). In the wake of his reflection, and after investigating motivation in a range of academic contexts, we are now able to present our own model, which is dynamic, weighted, and polytomic (Raby, 2007). After presenting cognitive ergonomics as a new pathway for research in second language acquisition, we shall present the results of our investigations in foreign language learning motivation in technologically enhanced contexts, outlining major methodological difficulties pertaining to this sort of this grounded research.
\end{abstract}

Keywords

motivation, cognitive and social psychology, instructional design, cognitive ergonomics, epistemology and methodologies, triangulation

\section{Introduction}

The question of ICT's motivational impact has paradoxically seldom been tested or investigated (Raby, 2009). The reason is that most writers on CALL impact tend to acknowledge their motivational function as something so evident that it doesn't really require in depth analysis. Considering this need for more research-based evidence, we have been conducting a series of empirical research, from 2001 to 2009, with a view to identifying the motivational impact of technology in academic settings - French schools and universities, taking into account different European languages. The aim of this paper is to present this interdisciplinary work, carried out in the University of Grenoble (the two research laboratories which have housed these programs were the educational science laboratory and the LIDILEM: laboratory of linguistics and first and second language didactics) by an ergonomic research team whose final aim was to analyze the impact of technologies on teachers' and learners' activities. The team consisted of two educational scientists, two cognitive psychologists; one statistician specialized in statistics for education, one social psychologist and one CALL specialist (several PHD and master dissertations were achieved). The work started in the educational sciences laboratory of Grenoble and is now continued in the LIDILEM still in Grenoble). In the wake of this collective work, the author of this paper has been able to build up an ergonomic motivational construct dynamic, polytomic and weighted. The focus of this paper is on methodological and conceptual issues that are to say something on the elaboration of a motivational construct suited to CALL activities and not only on research findings. For this reason, the author has sometimes felt it necessary to resort to the first person pronoun when she was expressing her own point of view, construction, method or findings and not a collective or general neutral standpoint.

The first part of this paper will briefly introduce main concepts of cognitive ergonomics in relation with the question of motivation in CALL contexts. The second part will present the ergonomic research procedure which we have progressively elaborated to carry out our empirical investigations and which 
falls in the new paradigm of triangular and blended methodologies (Dörnyei, 2008). In the third part we shall describe the evolution of our motivational CALL construct which was, to begin with, dynamic, process and task oriented and gradually became also polytomic and weighted. In conclusion, we shall re-examine this construct in the light of the recent developments of the ideal self-theories of motivation.

\section{The Cognitive Ergonomic Approach: an overview}

Ergonomics comes from the Greek ergon (work) and nomos (law, rules). Ergonomics seeks to establish the rules that govern people's activities while at work. Everywhere, in firms, factories, services, and in the educational world too, machines are becoming more and more sophisticated. Ergonomics is a unifying methodology which seeks to describe and interpret human and machine interactions (Cornfield \& Randon, 2001) in work situations.

Ergonomics studies operators in their workplaces, which means that they study their operative activity (Thorne, 2009a, 2009b) in a technological world. There are two main schools in ergonomics: the American and the European. Although they may seem contradictory in their approach, they are, in fact, complementary.

\section{The user-centred cognitive approach}

Cognitive Ergonomics is a hybrid discipline. It is not so much a science or an academic field as a methodology to carry out research about actual work situations. Cognitive and ergonomic psychology constitute the core theories, since the question at stake is what research can contribute to the elaboration of work situations/work places, training situations which will help the agents to develop and implement appropriate work knowledge, skills, competences (Rasmussen, 1993). Depending on the task domain (in our case L2 learning) and the workplaces which are investigated (in our case self-access rooms) and on the research questions (in our case strategies and rules of usage), all sorts of specialists may be called up to participate in the research team - engineers of course but also linguists, doctors, lawyers, sociologists and social psychologists, there is no limitation to the variety of participants. The ergonomic approach makes it possible to integrate different theories and points of view as will be shown later about CALL motivation.

The user-centred cognitive educational ergonomics which we have elaborated during the past 15 years belongs to this research paradigm. Our goal has been to analyze and model the operators/agents activity in CALL actual academic settings, specific and real work situations.

\section{Theoretical foundations}

\section{Mediated activities}

In most ergonomic surveys carried out by the French school, the study of work environments is grounded on the theories of mediated activities (Leontiev's activity theory, 1988; Vygotsky's theory of the instrument, 1986; Piaget's genetic psychology, 1963, 1965, Anderson, 2001). From these theories we receive the notion that we learn and change due to our interactions with our environments, in other words, that knowledge is socially and culturally embedded (Bandura, 1997, 2002; Rabardel, 1995a; Vygotsky, 1978, Elin, 2005). These theories claim that in any training environment the subjects' cognitive systems are never directly "connected" to the target domain and that the use of instruments during the working process generates a mediating process which affects the very content of the language which is being acquired (Bruillard, 1998; Chapelle et al, 2003, Levy). Their theory of the instrument encompasses material objects, artefacts, tools and instruments and seeks to explain how the appropriation of learning instruments brings into play collective schemes of usage within specific environments. Schemes express the biological capacity of any subject to assimilate new objects and new situations. A scheme is both a biological structure and an active organization of our experience that integrates the past and that evolves as it becomes adapted to new situations. When moving from the traditional language class to the self-access room or from class interactions to online interactions, 
learners build up new learning schemes. Because schemes are biological structures, they cannot be approached directly; the researcher has to hypothesize their presence indirectly.

The process through which teachers and learners (agents) turn artefacts (material objects) into instruments (that is to say a teaching or learning system) has been called instrumental genesis by Rabardel (1995). It is this process that we have tried to identify in self-access L2 learning. In this process, cognitive factors play a major part but, as will be shown later in this paper, motivational, affective, cognitive factors are equally of paramount importance. We have sought to build up a construct which would encompass these different factors.

\section{The user-centered ergonomic method}

First, it should be clear that there is nothing original about the data extracted and processed in educational ergonomics, since all researchers who desire to carry out an empirical research on CALL will either observe, or interview, or look at productions and interactions (Chapelle, 2000). Yet, the method that we use has specific traits:

- We start with descriptive constructs, what people do, not what they think or feel, which comes later since we believe that the only data we have a direct relation to are behaviours;

- We then build up inferential interpretative models to tentatively make sense of what the agents are doing (or not doing, by the way).

- We take into account non-linguistic variables, especially the physical, social and psychological ones.

- We try to work as much as possible on rather long periods, which means a minimum period of 6 to 8 months, more if possible to confirm and stabilize our findings.

- We try to establish the local validity of our results. By local validity we mean that quantitative results should be controlled using statistical tests which are suited to small scale measurements (Peers,) and that qualitative procedures should be rigorously conducted (Dornyei, 2008).

- As often as possible we associate qualitative and quantitative studies since we believe that they are complementary: performance and process are of interest.

- Finally, we use a triangular or blended methodology to solidify or improve our findings and to overcome the weakness that comes from single method, single-observer, single-theory studies (Jacob, 1990; O'Malley \& Valdez Pierce, 1996; Wiggins, 1998). In social sciences this method is often referred to under the label of triangulation.

\section{1) Behavioural data}

We usually start with behaviours recorded either thanks to human observers or, better nowadays, to video recording. They give us a first set of results in the form of patterns of behaviours. All investigations started with an observation of physical behaviours. Here are the different kinds of behaviours that we had selected to observe students working autonomously (Raby, Baillé, Bressoux \& Chapelle, 2003).

\begin{tabular}{|c|c|c|}
\hline Media selection & Instrumental behaviours & Work duration in min \\
\hline Computer & Preliminary inquiry & W1= less than 5 \\
Video & Makes pauses & W2 = between 5 and 10 \\
Didactic printed documents & Takes notes & W3=between 10 and 20 \\
Newspapers & Communicates with peers & W4=more than 20 \\
& Seeks for content help & \\
& Seeks for material help & \\
& Uses a dictionary & \\
\hline
\end{tabular}

Table 1: Instrumental behaviours displayed while using educational technologies 
We, then, process the grids into descriptive statistics:

\begin{tabular}{|c|c|c|c|}
\hline $\begin{array}{c}\text { Occurrences of media } \\
\text { selection in }\end{array}$ & $\begin{array}{c}\text { Students in guided } \\
\text { autonomy }\end{array}$ & $\begin{array}{c}\text { Students } \\
\text { working on their own }\end{array}$ & TOTAL \\
\hline Computer & 33 & 23 & 56 \\
\hline Video & 28 & 36 & 64 \\
\hline Audio & 11 & 5 & 16 \\
\hline Printed documents & & & \\
\hline
\end{tabular}

Table 2: Descriptive statistical analysis

We may also process the grids into navigation charts which enable us to identify the selection of media and the student's instrumental behaviours in a dynamic way. Navigation charts allow us to represent in a single graph rhythmical and temporal data. These variables are very important if we want to analyze the different ways in which students regulate their task. These charts are analyzed in two ways: variability among and inside learners and task/activity discrepancies. It is, in fact, the study of those charts that convinced me, in the first place, of the interest of the concept of task redefinition and motivation. Students who were externally motivated by passing the Cambridge First Certificate behaved according to a specific pattern, those who were working their English for its own sake (i.e. mainly watching videos) followed another pattern and those who were pursuing both goals followed a third pattern.

\section{2) Traces of the subjects' activity}

\section{Notes}

They consist of the linguistic studies of the traces left by the students in the form of note-taking, drafts, or screen captures or verbal productions. Screen captures, for instance, make it possible to retrieve the different screen pages accessed by a student while working on the computer and this contributes to a better understanding of how students have regulated their task (Raby and Penilla, 2008).

\section{Performances}

The second sort of behavioural data consists of the written and oral productions of the learners: essays, exercises, dialogues, web pages, oral interactions, etc. They are a visible concrete "expression" of the language capacity of the learners and they can be analyzed from different viewpoints (discourse analysis, interlanguage, language comprehension, cognitive difficulties or linguistic difficulties, for instance). However, the great bulk of recent studies in work analysis converge in saying that the way in which subjects redefine their task all along the working process weighs a lot on the mental processes in progress (Almaberti, 1991; Chambers and Davies, 2001; Levy, 1997; Chapelle, 2001). Therefore, we need to build up a third sort of data pertaining to the subjects' motivational and affective factors.

\section{3) Mental data}

To extract what agents' mental representation of their work before, during and after activity, we resort either to questionnaires, such as the ones broadly used to study language learning strategies (O'Malley \& Chamot, 1990) or motivation (Dornyei, 2000; 2001). They give us a preliminary view of the issue at stake and put us on the track of relevant further investigations. Usually, this leads us to carry out interviews in order to probe into one question in detail and to allow implicit ideas or feelings to emerge. We use questionnaires to extract two different kinds of information: on the one hand we try to know how students or teachers have redefined their task; on the other hand we try to know how they feel about the achieved task. In the first case we use pro-active questionnaires which are passed just after students have received instructions and just before they set out to work. Questions roughly take this sort of form:

- What do you have to do or are you going to do now? 
- What instruments can you use to do this task?

- What constraints do you have? (length of your production and time available)

Then, we use retro-active/post-actional questionnaires to see how students evaluate their tasks. They are administered right after task completion. We analyze them in the light of attribution theory (Weiner, 1980). Attribution theory assumes that all individuals use a number of ascriptions to explain what has happened to them and to interpret past events ("I failed because I did not read the instructions carefully") and to predict the results of achievement-related events ("Therefore, next time I will be more careful and I will succeed").

Yet, generally speaking, questionnaires yield a rather limited view of what teachers or students actually think and feel about their work. For this reason, we also use interviews or journals which we analyze in the framework of content and discourse analysis. Recently we have started using an approach based on the combination of two theories: discourse analysis and social cognitive psychology (Ghiglione et al, 1998). These researchers have developed a computer application Tropes which carries out an automated analysis of discourses (for more information, see Acetic's home page). Thanks to Tropes, we are able to extract implicit messages that would have escaped us if we had analyzed interviews or journals in an ad hoc manner; besides, it allows systematic comparisons of different discourses.

On the upper right box, the text that is being analysed has been broken down into sentences. The words in red correspond to the linguistic categories examined in the left box. The menu, in the upper left box describes the different categories which can be analysed (semantic and syntactic). The graph in the lower box, on the right, represents the proximities between two linguistic categories in the passage that is being analyzed and which can be seen above.

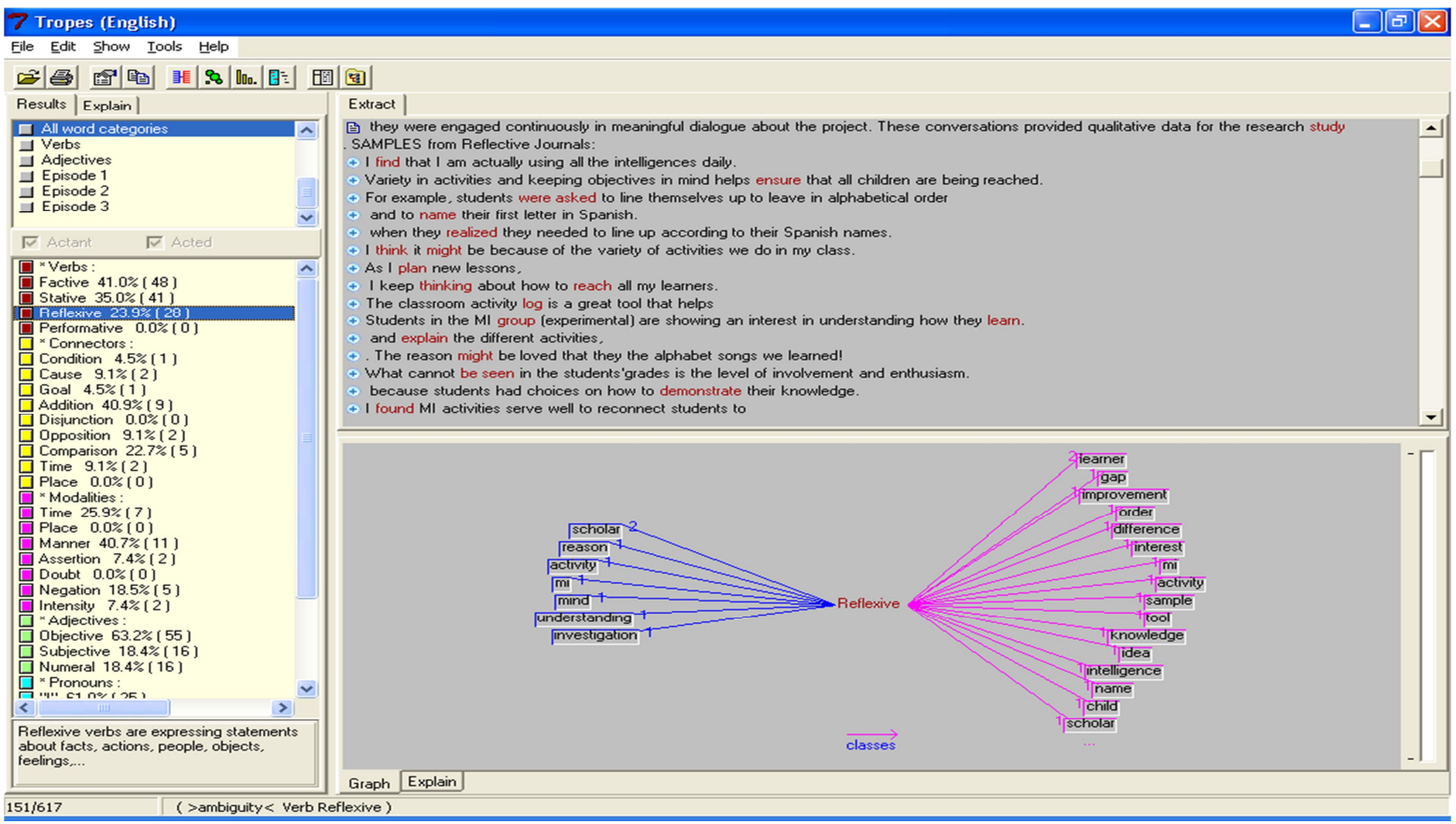

Figure 1: Tropes interface, a semantic and syntactic process 


\section{4) Data confrontation}

Assuming researchers have been able to gather the different data mentioned required by the triangular method, they might find themselves faced with two difficulties. The first one lies in the very different nature of the data: you can't add behaviours to representations any more than you can add feathers to lead; the second difficulty lies in the fact that often the different data do not corroborate (and sometimes clearly contradict) one another (Maxwell, 1996). In one survey, we had interviewed learners just after the realization of their communicative task (a chat on the web); as it happened, some learners were quite happy with their work although they had hardly been engaged in a real communication in the foreign language, while others were very critical of their productions whereas they had, in fact, done quite well from the teacher's point of view, considering the task difficulty. In such situations the difficulty is solved thanks to a theory which makes sense of the contradiction. Often, several theories are needed because learning or teaching seen not only as achievements or performances but also as a psychological and social processes, call for a superior comprehensive social constructivist construct:

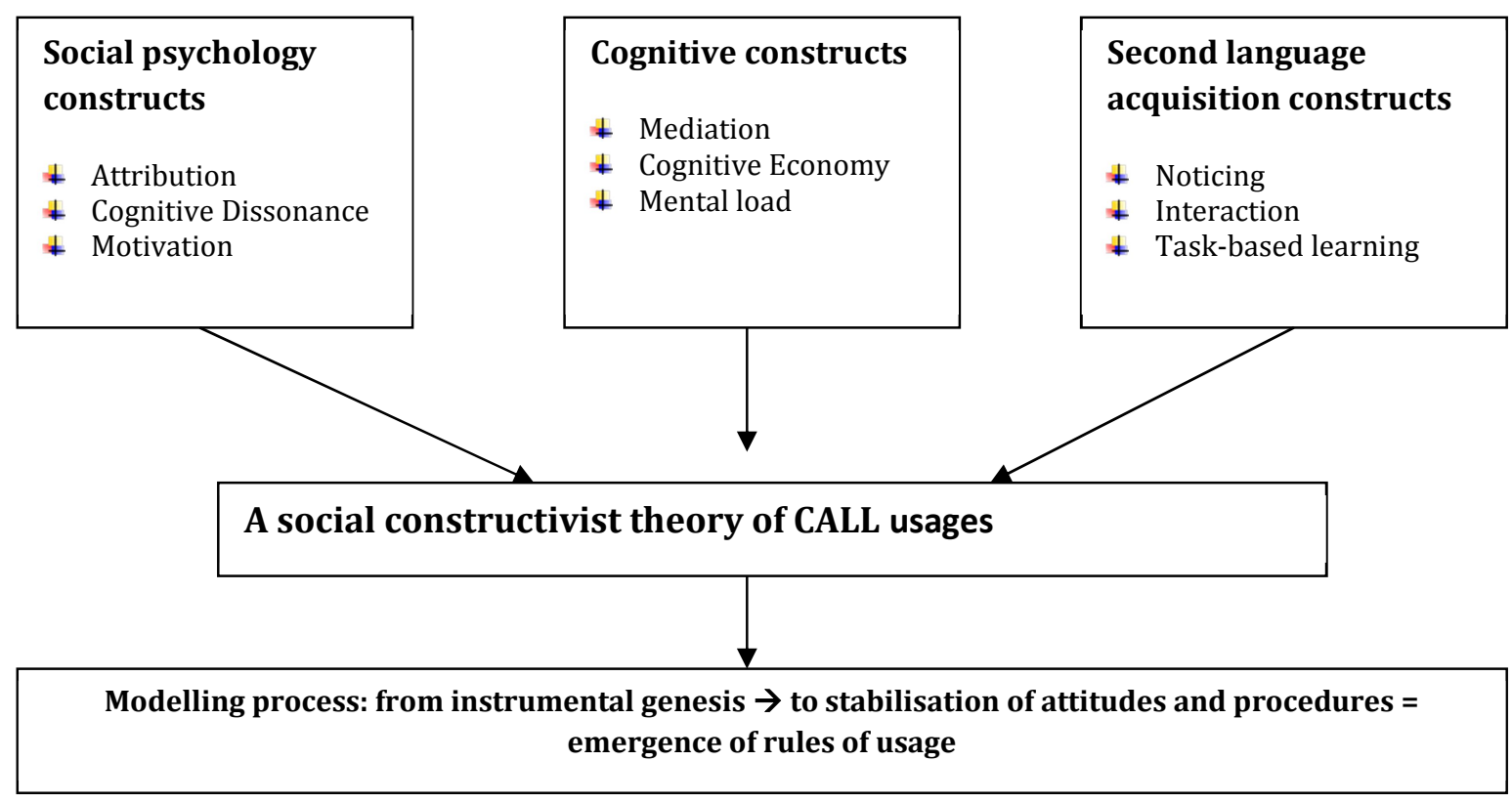

\section{On the way to motivation}

Generally speaking our investigations were focused on the cognitive mechanisms at work in autonomous language learning and carried out in different language centres or schools. Most of the time the research took place in the self-access room but we also often observed the same agents (teachers, tutors or learners) in traditional settings and in the self-access room. Progressively, as we were discovering how often the students' or the teachers' activity diverged from the designers' expectations, we found that cognitive explanations were not sufficient to account for these discrepancies or to explain the agents' strategies or rules of usage. Original beliefs, creeds, idiosyncratic representations, heuristic procedures emerged from our observations and formed a motley, heterogeneous picture of the selfaccess rooms as learning systems or arrangements (devices). It was not that this picture did not make sense but rather that actual users displayed a variety of rationalities which depended on their past experience, their goals and their competences (knowledge and skills). Gradually, we became convinced that the best possible accounts of language memorization, language comprehension or language production offered by cognitivists or CALL specialists would not work if a teacher or a learner was unwilling to work or ceased to work. Motivation thus became to emerge as an essential element of the 
language learning or teaching process not just a side issue reserved to social psychologists or sociolinguists (Van Lier, 2007; Norton, 1995).

\section{The Dynamic Polytomic Weighted Construct}

Cognitive and affective traits interact in the creation of a CALL work arrangement.

Six language teachers, teaching five different languages, were observed during twenty months in two work situations: a traditional language class versus a tutored language class in the self-access room. They were supposed to deliver the same course since they had collaboratively conceived it: a remedial course for intermediate learners in the traditional situation; a tutored course, named "guided autonomy" for the CALL course.

Since those teachers had been trained to teach in the traditional way and the tutored way was the new pattern, traditional teaching strategies were considered as the norm to which new strategies could be compared.

The comparison of the two situations bore on three main variables: the time variable (how much time was devoted to a given activity) the interaction variable (what form of interaction with the pupils had taken place) and finally the media variable (what sort of media did they use while teaching). In the light of Piaget's genetic theory, two cognitive schemes of usage (assimilation+accommodation) emerged from the findings, to which we have added another stage derived from the motivational analysis of the interviews: the refusal scheme.

Following the ergonomic methodology, we have confronted each teacher with the findings and asked them to try and explain the various strategies they used, particularly how and why they used any given medium, if any. Then, we interviewed them about how they saw their role in that language centre, whether they liked it, what improvements they would make, what worried them, etc.

Three patterns emerged which did not exactly match up with the cognitive patterns. The accommodating/motivated teacher was also enthusiastic and internally driven. He seemed to derive a lot of self-esteem from the fact that he was able to assist the students and not pilot their work. On the other hand, the assimilating/mixed feelings teachers showed a blended motivational profile. On one side, their ought to be professional selves were strong: to become innovators, to become more and more experts in their use of the technology, to imagine a pedagogy better curtailed to each students' profile and to lead them on the path of autonomy. Yet, on the side, they were reluctant to adopt the role of tutors because their ought to be selves somewhat contradicted their ideal professional selves (Maher, 1986; Julkunen, 2001). The first reason was that the technology induced a loss of control over the learners' action. They expressed the feeling that the computers somehow created a sort of physical and mental barrier between them and their students preventing direct interaction. The second reason was that the tutor role meant a change in their professional identity which they had not been prepared for. They had been trained as language teachers, the very embodiments of language knowledge and correction and cultural enrichment. Turning into tutor meant a change of the goals to be pursued since the autonomous form of work and the mastery of the technology occupied a large place in their interactions with the students, greater than the foreign language itself.

More interestingly, the assimilating/refusal teacher who completely ignored the learning system was also clearly internally driven, which proves that internality is not a guarantee of a strong motivation in any learning environment.

\section{The symbolic value of technology and its motivational impact during goal setting and task transposition}

\section{A serendipitous trip to the world of demotivation}

It is not often that researchers dealing with task motivation make demotivation the object of their research. The problem is precisely that once participants have dropped out it is difficult to get in touch with them to interview them about their reasons for dropping out or reluctance to continue with the project. 
The Tell Me More project (Raby, 2004) offered me a serendipitous trip into the world of demotivation. That sojourn has deeply marked my reflections on motivation since for some participants the experience ended in a complete breakdown. As a matter of fact, the project involved two sorts of learners: teacher training students and members of staff of the teacher training colleges. The latter were working either in the accountancy department or in the personnel department and it is with those participants that the project utterly failed. With the passing of time, I am now convinced that the final reason for that failure was the fact that the different actors in that project, namely the management of the college, the research team and the employees, were not pursuing the same goal.

A six month self-assisted language learning project was built up involving: tutor-assisted language learning with TMM in the self-access room, self-assisted work at home, and distance-based assistance by mail with each tutor being in charge of 8 employees and the use of the beta version of the network TMM programme.

\section{Motivation in CALL contexts is dynamic, unstable and fragile}

Motivation was high before and at the start of the project. At the beginning, employees had to wait because the engineers had not finished installing the tutoring functions. We knew that such a delay could undermine the employees' motivation, so the firm agreed to provide them with a normal version of the program which they could freely use at home. They were quite happy with this although they found it quite hard to manage on their own.

Later, the tutorial version was installed and they were able to correspond with their tutors by mail.

After 2 weeks, one member of the personnel department asked me if the network version could be installed in the department's offices. The reasons were that the time slots available when they could go to the self-access room were not convenient, and although they had too little time to work on their project at home, they could work in their office at lunch time instead of lunching at the canteen.

I asked AURALOG if it was possible and they equipped all the offices of the personnel department with TELL ME MORE.

A few days later, I was asked to go and see the head of the college on account that there was an urgent problem to be solved. He explained that he had recently received a letter from the college staff union and had had a discussion with the leader of the Union. There was a big problem with the TMM project.

The problem was as follows: it had been impossible to equip the accountancy department with the software (a fact that I was unaware of) and the Union letter denounced the project in general, and me specifically, for not treating employees fairly, favouring some of them at the expense of others.

\section{The symbolic value of technology: it participates in forming an "ideal-professional self"}

The head of the college soon organised a meeting during which the engineer explained to the employees that the beta version of TMM could work with PCs (installed in the personnel department) and not with Macs (installed in the accountancy department) and that was the only reason why accountants had not been offered it.

In the end, it was decided to uninstall the network version in the personnel department in order to fend off denunciations over the inequity of treatment. However, employees from both departments started deserting the self-access room. The accountancy staff claimed they had too much work preparing the budget to carry on with the course; the personnel staff claimed that it was great when they could work at lunch time, but now without the program in their office, it was not convenient at all. The project ended up a total failure. The interviews we conducted with a few "drop-outs" confirmed the idea that processes taking place in work situations are deeply rooted in socio-cultural influences (Dörnyei, 2009; Norton, 1995). In these valued-loaded environments the technology takes on a specific, symbolic value. In the case of our experiment, interviews showed that the actual drive triggered by the technology was not related to its primary, basic function of cognitive mediation but to a value function linked to theories of the selves: self-image, self-confidence, self-esteem, and above all, future, ideal, selves. 
There exists a professional idealized self, embedded in the general personal ideal self, defined by Marcus (1986), Higgins (1987) and Higgins \& al. (1985). It is very much related to the way in which an employee perceives himself or herself as a member of an institution in general and perhaps even more, within this institution, as a member of a department, a faculty, a school, a team, etc. This selfrepresentation commands the social cognitive act of future planning. In the TMM experience, by learning how to use the software employees were bound to become computer literate and foreign language literate. Since in most firms or institutions, such opportunities are usually offered to the managerial staff not the English Executive Senior Management project was likely to satisfy an ideal future self in a way that no-one had imagined might become a reality. This was perhaps the gist of the project, rather than the goal of mastering a foreign language. When they found out that it did not seem so important to the managerial staff that some employees should do without the technology, their selfesteem was undermined. As a consequence, suddenly a second rank motivational factor - "equipment in the office" - became a first rank factor - "without the equipment in the office, we can't work" - of symbolic nature.

During the discussions a significant misunderstanding took place. We (the research team) apologized about the casual way in which we had organised the registration. We explained that we had let them freely apply on a personal basis because this program had been set up to satisfy personal motivations -independently of the work these employees were performing in their department. But to the employees, things were quite different. They felt that this language training program was an actual part of their work, that they were doing this on a professional basis and not on a personal basis, on behalf of the teacher-training college and not on their own behalf. When they found out that the program had been launched rather haphazardly, at the initiative of AURALOG and the research team and not really at the initiative of the college's managerial staff, they realized that the goal of the managerial staff was more to please them, to satisfy their expectations rather than to improve their linguistic competence. As a consequence, because their goals were different, the constraints imposed on the project were seen differently. For the head of the college, they would not attend the languagetutored class during their normal work time, whereas for them (and for us, the research team) it was clear that they would be freed from work. It showed that once the project had been voted, each party had begun to transpose the task, building up their own fantasy-driven arrangement, and a lack of goal negotiation was certainly the ultimate reason for the failure of this project.

To sum up, the TMM project showed that in CALL professional contexts the technology is fraught with values which help to create an ideal professional self. It also hinted that motivational factors should not just be distinguished only from in terms of their nature (self-esteem, goals, action control, etc.), but also in terms of their weight. A goal or an instrument which may be seen as essential to motivation at one point, or in one experiment, or for one participant, may become a second rank factor, not essential at other times. In this way, the TMM project puts us on the way to a weighted model of motivation (Raby, 2004, 2007).

\section{A weighted construct}

The ESCALE project confirmed the weighted characteristic of motivational factors. Essentially, we had planned to test a sort of motto in CALL literature that a web-based L2 scenario is necessarily more motivating than a traditional scenario based on printed documents. In addition, borrowing from mainstream theories, we had listed a number of factors whose existence was deemed to predict a strong motivation.

\section{Technology is a first rank motivational factor}

The statistical findings yielded by the questionnaires proved this assertion wrong. Pupils working with the printed scenario and the Web scenario had the same level of expectation (respectively $47 \%$ and $46 \%$ ) and appraised the project in much the same way (respectively $70 \%$ and $72 \%$ ). They were also 
both ready to engage in a new one (respectively $82 \%$ and $85 \%$ ). Their performance (intermediate language tasks and creation of the home/front page of their papers) was of the same quality.

These results and many others in ICT literature show that it is not the technology in itself that is actually motivating; it is the pedagogical project which usually goes with it since most of the time CALL teachers propose meaningful, socially relevant tasks in keeping with the European Framework recommendations.

\section{Yet the technology may greatly enhance motivation}

The "hook" function attracts agents (Raby, 2007), but its motivational impact may soon wear off if the technology is not user-friendly and if the agent lacks training and is unable to use it in such a way that it efficiently assists them in the execution of their tasks. I have examined the different ways in which the technology as such (not the task) may enhance or undermine motivation and established five motivating functions (Raby, 200è, 2008): the hook function, the regulative function, the restore function, the creative function and the communicative function.

\section{A polytomic construct}

All investigations have shown that the technology is like Aesop's tongue: It is not good or "right" or "efficient" in itself: the same factor may act in a positive /motivational or negative/demotivational way, or even have no impact at all neutral/amotivational. In all three investigations, we found out that the characteristics of the project which the literature had predicted as motivational happened to appear as demotivational or neutral to some learners. Here are a few examples:

1. The fact that the web pages would be published on the school/university site, a socially meaningful goal, was deemed to be a source of motivation. In fact it was often said to be a source of stress instead of motivation by many learners, while for other learners it had no particular influence.

2. The fact that the web pages would be assessed and marked was either a source of positive or negative reinforcement for the learners, depending on their linguistic self-confidence (Noel, Pon \& Clement, 1996), or again had no influence at all.

3. The fact that in some cases the learners were offered the opportunity to collaborate was usually found to be very stimulating (Mangenot \& Bouchard, 2001; Deaudelin \& Nault, 2003; Levy, 2006), but for some learners, it was a waste of time and would prevent them from doing quality work.

4. The fact that they were given a lot of learning aids (linguistic, cultural and computer, and all sorts of templates) was found motivating by some learners but the majority of the pupils and students did not even look at them if their tutor did not insist that they might be useful

Those findings led me to coin the notion of a polytomic construct. Polytomic meaning that one factor (variable) may take on diverse concretizations, depending on whether its impact is positive (+), negative (-) or neutral. Some statistical models such as Multiple Correspondence Analysis (Benzecri, 1992) are particularly interesting to use when processing the data in this perspective (Raby \& al, 2003). It seems to me that in a qualitative approach to CALL, it is important to be aware that a negative effect, or the absence of an effect, is as meaningful as the positive effect of a motivational factor. Mental states of denial or refusal of a potential source of motivation often explain why an expected motivating factor provided by the environment does not perform motivation functions.

\section{Provisional conclusion}

The bulk of modern research focuses on the self and internal factors. I believe that working in professional situations and technologically enhanced situations compels researchers to pay attention to the external factors. From Otto and Dörnyei we have borrowed a dynamic model because this model was concerned with education/task/work motivation. Later, they elaborated a new model aiming at synthesizing diverse theories, which could be applied to any L2 environments.

The new construct - the "L2 Motivational Self-System" attempts to synthesize a number of influential approaches in the field (e.g. Gardner 1985; Noël 2003; Ushioda 2001) and at the same 
time broadens the scope of L2 motivation theory to make it applicable in diverse language learning environments in the current, increasingly globalized world. [Dörnyei, 2009, p. 212]

The consequence of the enlargement of the model is that the motivational factors of the learning environments tend to lose ground to the self factors. With this modern trend, I believe that external sources of motivation in professional contexts do not receive sufficient attention for two reasons. The first one is that since Gardner's seminal, pioneering work, most theories see the extern (external, extrinsic, externally driven) motivation as the wrong motivation, the one which doesn't last and doesn't really fuel actual language enjoyment and progress. It seems to me that this is due to confusion between the sources of motivation and motivation itself. Motivation being a mental state, there is no external motivation, it can only be internal. Motivation doesn't exist as a real objective reality dormant in the individual's' mind and waiting to be unveiled by researchers. Motivation is a construct built up by scientists to account for a specific individual's behaviour. Many constructs claim that the subjects' cognitive factors are more important than the work environment. This dichotomic vision seems to me (and other writers) wrong because it rests on a homeostatic model. Piaget (1967), Bruner (1983), Vygotsky (1978) and Nuttin (1980) all agree that human beings develop through their interactions with their environment. Without external sources of motivation there would be no motivation; without the individuals' cognitive and social processing of these sources there would be no motivation. As a consequence, it seems to me that the dialectical approach best serves motivational research. It is through interacting with peers, teachers and people and machines thanks to the internet that pupils and students will learn and develop an L2 or fail to learn. To reject the importance of external factors comes down to denying all development theory, in particular the motivational one. Dörnyei seems aware of this when in his latest book (Dörnyei, 2014).

To conclude, the web 2 revolution is coming as a challenge for ergonomic researchers since the frontier between professional/work situations and everyday life/home situations is fading away. In some countries, perhaps in a few years, the very notion of academic or institutional L2 learning will lose its significance. In other countries it will jeopardize ruling pedagogical models and the technology will be seen as an evil weapon in the hands of globalizing forces. To meet the challenge of understanding and analyzing the revolution that is taking place, it is necessary to alter our research methods and models a process which is already underway (Lasagabaster \& al, 2014).

\section{References}

Anderson, J. R. (2001). Cognitive psychology and its implications. San Francisco: Freeman.

Almaberti, R., Montmollin, M., \& Theureau, J. (Eds.). (1991). Modèles en analyse du travail. Liège: Mardaga.

Annett, J., \& Neville, A.S. (2000). Task analysis. New York: Taylor \& Francis.

Bandura, A. (1997). Self-efficacy: The exercise of control. New York: W. H. Freeman.

Bandura, A. (2002). Social cognitive theory of mass communication. In Bryant, E., Jennings, Z., Zilmann, D. \& Dof, B. (Eds.), Media effects: Advances in theory and research (2nd ed.) (pp. 121153). Mahwah, NJ, US: Lawrence Erlbaum Associates.

Bruillard, E. (1998). L'ordinateur à l'école: de l'outil à l'instrument. Sciences et Techniques Educatives, 5(1), 65-78.

Benzecri, J. P. (1992). Correspondence Analysis Handbook. New York: Dekker, P.

Bressoux, P. (2008). Modélisation statistique appliquée aux sciences sociales. Bruxelles: DeBoeck.

Chapelle, C. (2001). Computer Applications in Second Language Acquisition. Cambridge: Cambridge University Press.

Chapelle, C. (2003). English language learning and technology: Lectures on teaching and research in the age of information and communication. Amsterdam: John Benjamins Publishing.

Cornfield, D. \& Randon, R. (Eds.). (2001). Worlds of work: Building an international sociology of work. New York: Plenum Press. 
Dörnyei, Z. (2001). Teaching and researching motivation. London: Longman.

Dörnyei, Z. (2003). Attitudes, Orientations and Motivations in Language Learning: Advances in Theory, Research, and Applications. Language Learning, 53(Supplement 1), 3 - 32.

Dörnyei, Z. (2007). Research methods in applied linguistics: Quantitative, qualitative and mixed methodologies. Oxford: Oxford University Press.

Dörnyei, Z. \& Ushioda, E. (2009). Motivation, language identities and the L2 self. Future research directions. In Dörnyei, Z. \& Ushioda, E. (Eds), Motivation, language identities and the L2 self (pp 350-355). Bristol: Bristol multilingual papers.

Dörnyei, Z., Macinter, P., \& Alastair, H. (2014). Motivational Dynamics in Language Learning. Bristol: Bristol Multilingual Matters.

Hoc, J. M. (1992). Psychologie cognitive de la planification. (2nd ed.). Grenoble: Presse Universitaires de Grenoble.

Hoc, J. M. (1996). Supervision et contrôle de processus. La cognition en situation dynamique. Grenoble: Presses Universitaires deGrenoble.

Lasagabaster, D., Aintzane, D., \& Sierra, R. M. (2014). Motivation and foreign language learning. Amsterdam: John Benjamin.

LEontiEv, A. (1978). Activity, consciousness and personality. Englewood, Cliffs: NJ: Prentice Hall.

Mangenot, F. (2001). Multimédia et apprentissage des langues. In Crinon, J. \& Gautellier, C. (Eds.), Aprendre avec le multimédia et Internet (pp. 59-74). Paris: Retz.

Markus, H., \& Nurius, P. (1986). Possible selves. American Psychologists, 41, 954 - 969.

Maxwell, J. (1996). Using qualitative research to develop causal explanations. In Harvard Project on Schooling and Children. Harvard: Harvard University.

Noel, K. A., Pon, G., Clement, R. (1996). Language, identity and adjustments: The role of linguistic selfconfidence in the acculturation process. Journal of language and social psychology, 15, 246-264.

Nuttin, J. (1980). Théorie de la motivation humaine. Paris: PUF.

Norton, P. (1995). Social identity, investment, and language learning. TESOL Quarterly, 29(1), 9-31.

O’Malley, J. M. \& Chamot, L. U (1990). Learning Strategies in Second Language Acquisition. Cambridge: Cambridge University Press.

Rabardel, P. (1995) Les hommes et les technologies. Approche cognitive des instruments contemporains. Paris: Armand Colin.

Raby, F. (2007). A triangular approach to motivation in Computer Assisted Autonomous Language Learning (CAALL). Recall, 19(2), 181-201.

Raby, F. (2008). Comprendre la motivation en LV2: quelques repères venus d'ici et d'ailleurs. Les Langues Modernes, 3, 9-16.

Raby, F. (2008). La question des méthodes et des outils de recherches dans la Didactique de l'Anglais comme recherche appliquée. Journée d'étude en didactique de l'anglais, IUFM de Paris.

Rasmussen, J. (1993). Analysis of tasks, activities and work in the field and in laboratories. Le travail humain, 56, 133-155.

Thorne, S. L. (2009a). "Community", semiotic flows, and mediated contribution to activity. Language Teaching, 42(1), 81 - 94.

Thorne, S. L., BLACK, R. W. et al. (2009b). Second language use, socialization, and learning in interest communities and online games. The Modern Language Journal, 93 (Issue Supplement s1), 802-821.

Vygotsky, L. S. (1978). Mind in society. Cambridge, MA: Massachusetts Institute of Technology Press.

Vygotsky, L. S. (1986) Pensée et langage. Paris, La Dispute.

Van Lier, L. (2007). Action-based Teaching, Autonomy and Identity. Innovation in Language Learning and Teaching, 1(1), 46-64.

Wiggins, G. (1988). Educative Assessment. San Francisco, CA, Jossey-Bar. 


\section{Contact}

Françoise Raby, Professor,

Chair of the LAIRDIL laboratory

IUT A, 115 B, route de Narbonne

31077 Toulouse Cedex 4, France

fraby@lairdil.fr 